\title{
Deletion of the Mitochondrial Matrix Protein Cyclophilin D Prevents Parvalbumin Interneuron Dysfunction and Cognitive Deficits in a Mouse Model of NMDA Hypofunction
}

\author{
${ }^{\text {D }}$ Aarron Phensy, ${ }^{1}$ Kathy L. Lindquist, ${ }^{1}$ Karen A. Lindquist, ${ }^{1}$ Dania Bairuty, ${ }^{1}$ Esha Gauba, ${ }^{2}$ Lan Guo, ${ }^{2}$ Jing Tian, ${ }^{2}$ \\ Heng $\mathrm{Du},{ }^{2}$ and ${ }^{\mathbb{S}}$ Sven Kroener ${ }^{1}$ \\ ${ }^{1}$ School of Behavioral and Brain Sciences, The University of Texas at Dallas, Richardson, Texas 75080, and ${ }^{2}$ Department of Biological Sciences, The \\ University of Texas at Dallas, Richardson, Texas 75080
}

Redox dysregulation and oxidative stress are final common pathways in the pathophysiology of a variety of psychiatric disorders, including schizophrenia. Oxidative stress causes dysfunction of GABAergic parvalbumin (PV)-positive interneurons (PVI), which are crucial for the coordination of neuronal synchrony during sensory and cognitive processing. Mitochondria are the main source of reactive oxygen species (ROS) in neurons and they control synaptic activity through their roles in energy production and intracellular calcium homeostasis. We have previously shown that in male mice transient blockade of NMDA receptors (NMDARs) during development [subcutaneous injections of $30 \mathrm{mg} / \mathrm{kg}$ ketamine (KET) on postnatal days 7 , 9, and 11] results in long-lasting alterations in synaptic transmission and reduced PV expression in the adult prefrontal cortex (PFC), contributing to a behavioral phenotype that mimics multiple symptoms associated with schizophrenia. These changes correlate with oxidative stress and impaired mitochondrial function in both PVI and pyramidal cells. Here, we show that genetic deletion (Ppif-/-) of the mitochondrial matrix protein cyclophilin D (CypD) prevents perinatal KET-induced increases in ROS and the resulting deficits in PVI function, and changes in excitatory and inhibitory synaptic transmission in the PFC. Deletion of CypD also prevented KET-induced behavioral deficits in cognitive flexibility, social interaction, and novel object recognition (NOR). Taken together, these data highlight how mitochondrial activity may play an integral role in modulating PVI-mediated cognitive processes.

Key words: electrophysiology; medial PFC; mitochondria; NMDA receptor; parvalbumin interneuron; schizophrenia

Significance Statement

Mitochondria are important modulators of oxidative stress and cell function, yet how mitochondrial dysfunction affects cell activity and synaptic transmission in psychiatric illnesses is not well understood. NMDA receptor (NMDAR) blockade with ketamine (KET) during development causes oxidative stress, dysfunction of parvalbumin (PV)-positive interneurons (PVI), and long-lasting physiological and behavioral changes. Here we show that mice deficient for the mitochondrial matrix protein cyclophilin D (CypD) show robust protection from PVI dysfunction following perinatal NMDAR blockade. Mitochondria serve as an essential node for a number of stress-induced signaling pathways and our experiments suggest that failure of mitochondrial redox regulation can contribute to PVI dysfunction.

Received Apr. 15, 2020; revised May 28, 2020; accepted June 22, 2020.

Author contributions: A.P., H.D., and S.K. designed research; A.P., K.L.L., K.A.L., D.B., E.G., L.G., J.T., H.D., and S.K. performed research; A.P., K.L.L., K.A.L., L.G., H.D., and S.K. analyzed data; A.P. and S.K. wrote the paper.

A.P. was supported by the National Institutes of Health (NIH) Grant F31MH118883 and the Eugene McDermott Graduate Fellows Program of The University of Texas at Dallas. S.K. was supported by The University of Texas at Dallas and by the NIH Grant R01AG053588. H.D. is supported by NHH Grants R01AG053588 and R00AG037716.

The authors declare no competing financial interests.

Correspondence should be addressed to Sven Kroener at kroener@utdallas.edu.

https://doi.org/10.1523/JNEUROSCI.0880-20.2020

Copyright $\odot 2020$ the authors

\section{Introduction}

Schizophrenia is a neurodevelopmental disorder in which genetic risk factors and early life stressors converge (Harrison and Owen, 2003). Genes involved in glutamatergic synaptic transmission figure prominently among both the rare (Timms et al., 2013; Pocklington et al., 2015; Sekar et al., 2016) and common (Pers et al., 2016) gene variants that contribute to the heritable risk for schizophrenia. In the frontal cortex, these genes are highly expressed early in development (Gulsuner et al., 2013; Birnbaum et al., 2015). Dysfunction of glutamatergic NMDA 
receptors (NMDARs) during neurodevelopment can disrupt maturation of interneurons (Zhang and Sun, 2011) and cause abnormalities in the GABAergic and dopaminergic systems in schizophrenia (Olney et al., 1999; Krystal et al., 2002; Catts et al., 2013). Aberrant NMDAR activity can therefore shift the cortical excitation-inhibition (E/I) balance (Insel, 2010; Lewis et al., 2012), leading to increased basal neural activity (Jadi et al., 2016), excessive glutamatergic release (Plitman et al., 2014), and oxidative stress (Hardingham and Do, 2016; Steullet et al., 2016). In support of this, NMDAR antagonists such as phencyclidine and ketamine (KET) induce a schizophrenia-like syndrome in healthy subjects and exacerbate symptoms in schizophrenic patients (Malhotra et al., 1997; Krystal et al., 2002; Anticevic et al., 2012). Pharmacological blockade or genetic deletion of NMDARs in rodents mimics many of the behavioral symptoms seen in patients with schizophrenia, and it also reduces markers of GABAergic interneurons, including cells that express the calcium-binding protein parvalbumin (PV; Abekawa et al., 2007; Braun et al., 2007; Belforte et al., 2010). Reductions in PV expression are a core finding of postmortem studies in schizophrenia patients (Olney et al., 1999; Lewis et al., 2005; Akbarian and Huang, 2006) that is replicated by virtually all animal models of the disease (Jiang et al., 2013; Steullet et al., 2017). Fast-spiking PV-expressing interneurons (PVIs) have a unique metabolic profile that is reflected in a large number of mitochondria and enriched cytochrome $c$ oxidase (Kann and Kovács, 2007), which seems to make them particularly susceptible to external stressors during development (Hardingham and Do, 2016; Steullet et al., 2017).

Mitochondria are crucial regulators of oxidative and nitrosative stress (Chen et al., 2003; Li et al., 2004), and transcriptomic, proteomic, and metabolomic studies in postmortem samples from subjects with schizophrenia indicate alterations in the expression of several proteins associated with mitochondrial function (Prabakaran et al., 2004; Altar et al., 2005; Iwamoto et al., 2005; Hjelm et al., 2015). Altered levels of ATP and mitochondrial dysfunction in the frontal lobe are correlated with negative symptoms, as well as cognitive and memory deficits in schizophrenia (Ben-Shachar and Laifenfeld, 2004; Rajasekaran et al., 2015). Oxidative and other cellular stresses promote translocation of the mitochondrial matrix protein cyclophilin $\mathrm{D}$ (CypD) to the inner membrane. This translocation triggers the opening of the mitochondrial permeability transition pore (mPTP) (Connern and Halestrap, 1994; Baines et al., 2005), which is important in glutamate excitotoxicity that results from overactivation of glutamate receptors and subsequent excessive calcium entry into the cell (Schinder et al., 1996; White and Reynolds, 1996). Prolonged CypD-mediated opening of mPTP causes collapsed mitochondrial membrane potential, elevated mitochondrial reactive oxygen species (ROS) generation, and lowered ATP production, leading to metabolic changes and ultimately cell death (Basso et al., 2005; Halestrap, 2010). Because CypD is a necessary component of the $\mathrm{mPTP}$, reducing CypD translocation to block mPTP formation can preserve mitochondrial function (Du and Yan, 2010).

Here, we investigated whether genetic deletion of CypD (Ppif-/-) can prevent changes in PVI function, prefrontal cortex (PFC) physiology, and behavior that develop in a well-characterized rodent model of NMDA hypofunction. Perinatal treatment with KET induced oxidative stress and reduced PV expression in the PFC of wild-type (WT), but not of Ppif-/-, mice. CypD deletion similarly protected against changes in glutamatergic transmission at PVI and deficits in cognitive flexibility, social interaction, and novel object recognition (NOR). These data indicate that mitochondrial redox regulation is an important contributor to PVI dysfunction and the resulting E/I imbalance that results from NMDAR hypofunction.

\section{Materials and Methods}

Transgenic ppif-/- mice

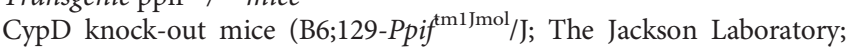
RRID:IMSR_JAX:009071) were crossed with G42 mice (CB6-Tg[Gad1EGFP]G42Zjh/J; The Jackson Laboratory; RRID:IMSR_JAX:007677) which express GFP in PVI neurons, to identify PV+ neurons in slice electrophysiology experiments. First-generation and second-generation breeders were selected and their WT (CB6-TgWT; Gad1-EGFP) and Ppif-1- (CB6-TgPpif-/-; Gad1-EGFP) offspring were used for experiments. All procedures were approved by the Institutional Animal Care and Use Committee of The University of Texas at Dallas.

\section{Perinatal KET treatment}

On postnatal day 7, 9, and 11 mice received subcutaneous injections of either saline or a subanesthetic dose of the NMDA antagonist KET (30 mg/kg; Ketathesia HCl, Henry Schein Medical). Both Ppif-/- and WT mice received either perinatal KET or saline injections, creating four groups: WT mice that received saline injections (WT-SAL); WT mice that received KET injections (WT-KET); Ppif-/ - mice that received saline injections (Ppif-/--SAL); and Ppif-/- mice that received KET treatment (Ppif-/--KET). All experiments were performed on adult male Ppif- $/-$ and WT mice (60-120 d old). Animals that participated in behavioral experiments were handled for $5 \mathrm{~min} / \mathrm{d}$ in the vivarium for two weeks before the test and then also in the room in which behavioral testing took place for $3 \mathrm{~d}$ before the test. On the day of testing, animals were transferred to the behavioral room at least $30 \mathrm{~min}$ before testing began. All behavioral tests and analyses were performed by experimenters blind to the experimental condition of the subjects.

\section{Immunohistochemistry}

Animals were perfused transcardially with saline for $2 \mathrm{~min}$, followed by $4 \%$ paraformaldehyde in $0.12 \mathrm{~m} \mathrm{PBS}$, at $4^{\circ} \mathrm{C}, \mathrm{pH}$ 7.4; Fisher Scientific) for $10 \mathrm{~min}$ using a peristaltic pump $(5.5 \mathrm{ml} / \mathrm{min}$; PeriStar Pro, WPI). Brains were postfixated in paraformaldehyde with $30 \%$ sucrose for $1 \mathrm{~h}$ and then transferred to $30 \%$ sucrose in PBS for $18 \mathrm{~h}$ at $4^{\circ} \mathrm{C}$. Coronal slices $(40 \mu \mathrm{m})$ were cut on a freezing microtome. Free-floating sections were incubated in rabbit anti-PV (1:2000 working dilution; Swant cata$\log$ \#PV 25, RRID:AB_10000344) in PBS and 0.3\% Triton X-100 (SigmaAldrich) for $36 \mathrm{~h}$ at $4^{\circ} \mathrm{C}$. Sections were washed three times for $10 \mathrm{~min}$ each in PBS before they were incubated in secondary 594 goat anti-rabbit (1:1000 working dilution; Jackson ImmunoResearch catalog \#111-585144, RRID:AB_2307325) in PBS and 0.3\% Triton X-100. Sections were washed, mounted, and coverslipped using Prolong Gold Antifade with DAPI (Thermo Fisher Scientific). To quantify PVI immunofluorescence, a minimum of four sections from each animal containing the prelimbic and infralimbic regions of the PFC were imaged on a confocal microscope (FluoView 1000, Olympus) at $20 \times$ magnification. The number of $\mathrm{PV}+$ cells were hand counted in ImageJ (National Institutes of Health), and DAPI-labeled cells were counted using the thresholding function in Image J to obtain the percentage of total PV + cells among all DAPI-labeled cells. In order to quantify 4-hydroxynonenal (4-HNE) levels in PVI free-floating sections were incubated in rabbit anti-PV (1:2000 working dilution; Swant catalog \#PV 25, RRID:AB_10000344) and mouse anti-4-HNE (1:1000 working dilution; Abcam catalog \#ab48506, RRID:AB_867452) in PBS and 0.3\% Triton X-100 (Sigma-Aldrich) for $36 \mathrm{~h}$ at $4^{\circ} \mathrm{C}$. Sections were washed three times for $10 \mathrm{~min}$ each in PBS before they were incubated in secondary 488 goat anti-rabbit $(1: 1000$ working dilution; Jackson ImmunoResearch catalog \#111-095-144, RRID:AB_2337978) and 647 goat anti-mouse (1:500 working dilution; Cell Signaling Technology catalog \#4410, RRID:AB_1904023) in PBS and $0.3 \%$ Triton X-100. To quantify 4 -HNE in PVI cells, PVI immunofluorescence confocal images $(20 \times$ magnification) from three sections of the prelimbic and infralimbic cortex were taken for each animal. Regions of interest (ROIs) were drawn around all PV + cells in cellSens 
(Olympus cellSens Software, RRID:SCR_016238) and the mean gray intensity of the 4-HNE signal for each cell was selected and averaged across each image and then across all three slices for every animal.

\section{GSH:GSSG assay}

In order to measure the ratio between reduced glutathione (GSH) and oxidized GSH (GSSG), GSH, GSSG, and total GSH were measured following the manufacturer instructions (GSH detection kit, catalog \#ADI900-160, Enzo Life Sciences). Sample preparation was performed by one researcher blinded to the treatment condition of the mice, and the order of sample preparation was pseudorandomly shuffled to minimize bias. In brief, animals were killed and the medial PFC (mPFC) containing the infralimbic and prelimbic cortex was dissected and homogenized in icecold $5 \%(\mathrm{w} / \mathrm{v})$ meta-phosphoric acid $(20 \mathrm{ml} / \mathrm{g}$ tissue), followed by centrifugation at $12,000 \times \mathrm{g}$ for $10 \mathrm{~min}$ at $4^{\circ} \mathrm{C}$. The resultant supernatant was collected for GSH detection. For the measurement of GSSG and total GSH, 2 м 4-vinylpyridine was added to the samples at a dilution of 1:50 (v/v). The samples were then incubated for $1 \mathrm{~h}$ at room temperature to derivatize reduced GSH. Afterward, the samples were diluted in the reaction mix buffer. The reaction was observed by immediately and continuously recording changes at an optical density of $405 \mathrm{~nm}$ by using a microplate reader (Biotek) for a total of $15 \mathrm{~min}$ at 1-min intervals. The concentrations of total, oxidized, and reduced GSH were normalized to the original wet weight of the tissue. All assays were performed on a 96well microplate reader so that data could be collected from each sample at the same time. Our reported GSH/GSSG ratios conform to the range of GSH/GSSG ratios between 2 and 100 that have previously been reported for brain tissue (Cruz-Aguado et al., 1999; Lipton et al., 2003; Zhu et al., 2006; Zhang et al., 2012; Hong et al., 2014; Zaghloul et al., 2014).

\section{Electrophysiology}

Electrophysiological experiments used GFP + hemizygous mice. Mice were anesthetized with urethane ( $3 \mathrm{~g} / \mathrm{kg}$ body weight; Fisher Scientific) and transcardially perfused for $1 \mathrm{~min}$ with gravity-fed ice-cold oxygenated $\left(95 \% \mathrm{O}_{2} .5 \% \mathrm{CO}_{2}\right)$ cutting artificial CSF (ACSF), consisting of the following: $110 \mathrm{~mm}$ choline (Sigma-Aldrich), $25 \mathrm{~mm} \mathrm{NaHCO}_{3}$ (Fisher Scientific), $1.25 \mathrm{~mm} \mathrm{NaH}{ }_{2} \mathrm{PO}_{4}$ (Fisher Scientific), $2.5 \mathrm{~mm} \mathrm{KCl}$ (SigmaAldrich), $7 \mathrm{~mm} \mathrm{MgCl}_{2}$ (Sigma-Aldrich), $0.5 \mathrm{~mm} \mathrm{CaCl}_{2}$ (Sigma-Aldrich), $10 \mathrm{~mm}$ dextrose (Fisher Scientific), $1.3 \mathrm{~mm}$ L-ascorbic acid (Fisher Scientific), and $2.4 \mathrm{mM} \mathrm{Na}^{+}$-pyruvate (Sigma-Aldrich). Immediately after, brains were extracted and coronal sections $(350 \mu \mathrm{m})$ of the frontal cortex were cut on a vibratome (VT1000S, Leica) in cutting ACSF. Slices were transferred into a holding chamber containing warmed $\left(35^{\circ} \mathrm{C}\right)$ recording ACSF and cooled to room temperature over a 1-h period. The recording ACSF consisted of the following: $126 \mathrm{~mm} \mathrm{NaCl}$ (Fisher Scientific), $25 \mathrm{~mm} \mathrm{NaHCO} 3,1.25 \mathrm{~mm} \mathrm{NaH} \mathrm{PO}_{4}, 2.5 \mathrm{~mm} \mathrm{KCl}, 2 \mathrm{~mm}$ $\mathrm{MgCl}_{2}, 2 \mathrm{~mm} \mathrm{CaCl}_{2}, 10 \mathrm{~mm}$ dextrose, $2.4 \mathrm{mM} \mathrm{Na}^{+}$-pyruvate, and $1.3 \mathrm{~mm}$ $\mathrm{L}$-ascorbic acid. For data collection, slices were transferred to a recording chamber affixed to an Olympus BX61WI microscope (Olympus) with continuous perfusion of oxygenated recording ACSF at room temperature. Whole-cell voltage-clamp recordings were obtained from pyramidal cells and PVIs in the prelimbic and infralimbic cortex using an Axon Multiclamp 700B amplifier (Molecular Devices). Data were acquired and analyzed using AxoGraph X (AxoGraph Scientific). Recording electrodes (WPI; 3-5 M $\Omega$ open tip resistance for pyramidal cells, 6-8 M $\Omega$ for interneurons) were filled with an internal solution consisting of the following: $130 \mathrm{~mm} \mathrm{CsCl}$ (Sigma-Aldrich), $20 \mathrm{~mm}$ tetraethylammonium chloride (Sigma-Aldrich), $10 \mathrm{~mm}$ HEPES (Sigma-Aldrich), $2 \mathrm{~mm} \mathrm{MgCl}_{2}$,

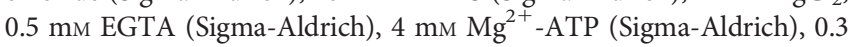
$\mathrm{mm}$ lithium-GTP (Sigma-Aldrich), $14 \mathrm{~mm}$ phosphocreatine (SigmaAldrich), and $2 \mathrm{~mm}$ QX-314 bromide (Tocris Bioscience). Theta-glass pipettes (Warner Instruments) connected to a stimulus isolator (WPI) were used for focal stimulation of synaptic potentials. Access resistance was monitored throughout the recording, and a $<20 \%$ change was deemed acceptable. Spontaneous EPSCs (sEPSCs) were isolated by blocking chloride channels with the addition of picrotoxin (75 $\mu \mathrm{M}$; Sigma-Aldrich) into the recording ACSF. Spontaneous IPSCs (sIPSCs) were isolated by blocking AMPA receptor-mediated events with 6-cyano-7-nitroquinoxaline-2,3-dione (CNQX; $20 \mu \mathrm{m}$; Sigma-Aldrich). Miniature events were isolated by blocking sodium channels with the addition of tetrodotoxin ( $1 \mu \mathrm{M}$; Alomone Labs). The frequency and amplitude of events were measured from $150 \mathrm{~s}$ (EPSCs) and $200 \mathrm{~s}$ (IPSCs) of continuous recording using MiniAnalysis (Synaptosoft) with a threshold set at two times the RMS baseline noise. The ratio of currents through NMDA or AMPA receptors, respectively, was obtained by clamping cells at $+40-\mathrm{mv}$ holding potential and applying local electrical stimulation. A compound evoked EPSC (eEPSC) was first recorded, then the AMPA component was isolated by washing CPP $[(+/-)-3-$ (2-carboxypiperazin-4-yl)propyl-1-phosphonic acid; $10 \mu \mathrm{M}$; SigmaAldrich] into the bath. A minimum of 15 sweeps each were average for the compound and AMPA-only eEPSCs. The NMDA component was then obtained by digital subtraction of the AMPA component from the compound trace. The peak amplitude of the NMDA and AMPA traces were used to calculate the NMDAR/AMPAR ratio. For all recordings a minimum of three mice were used per treatment group.

\section{Rule shifting}

Procedures for our rule-shifting task followed those previously described (Phensy et al., 2017b). Mice were food restricted to $85 \%$ of their freefeeding weight over two weeks and handled for at least $5 \mathrm{~min} / \mathrm{d}$. Testing took place in white wooden plus maze (each arm is $10 \times 34 \times$ $15 \mathrm{~cm}$, with a $10 \times 10 \mathrm{~cm}$ center area) under low ambient illumination. The arms were labeled East, West, South, and North for reference. On days 4-6, the maze was converted into a T-maze by blocking off one of the arms with a divider, and additionally, a visual cue (vertical black and white stripes on a $13 \times 10 \mathrm{~cm}$ plastic sheet) was placed alternately near the entrance of one of the two choice arms in a pseudorandom manner. During all days, reward pellets (Cheerio bits) were placed around the outside of the maze to prevent animals from using olfactory cues to infer the location of the reward. Mice were habituated to the maze over $3 \mathrm{~d}$. On the first day of habituation, four reward pellets (1/ 8th Cheerios bits) were placed in each of the arms of the plus maze. Animals were placed into the center of the maze and were allowed to freely explore the maze for $15 \mathrm{~min}$. If a mouse consumed all 16 pellets before the end of the habituation period, it was briefly placed in a holding cage while the maze was rebaited, and then the mouse was placed back into the maze until the end of the 15-min period. On the second day of habituation, arms were baited with two pellets each, and on the third day of habituation, only one food pellet was placed at the end of each arm. To reach habituation criterion, animals were required to consume all four food pellets at least four times within the 15-min period. All animals in this study reached this criterion on the third habituation day. On the following day (day 4), the plus maze was converted into a T-maze by blocking off one of the arms and the animals' turn bias was determined. Therefore, mice were placed in the stem arm and allowed to turn left or right to obtain a food pellet. After the mouse consumed the reward, it was returned to the stem arm and allowed to make another choice. If the mouse chose the same arm as on the initial choice, it was returned to the stem arm until it chose the other arm and consumed the food pellet. Once both food pellets were consumed the maze was rebaited and the next trial began. The direction of the initial turn chosen four or more times over seven trials was considered the turn bias. On the next day (day 5 , response discrimination), mice were trained on an egocentric task which required them to always turn toward one side (left or right, chosen opposite to the direction of their turn bias) to obtain the food reward. The location of the stem arm was pseudorandomly rotated among three arms (East, West, and South) to discourage mice from using an allocentric spatial strategy. During all trials, a visual cue was placed close to the entrance of one of the choice arms. Placement of this cue into the right or left arm varied pseudorandomly to balance the frequency of occurrences in each arm across blocks of 12 consecutive trials. Similarly, the order of the stem arms alternated pseudorandomly in a balanced fashion across blocks of 12 trials. Training continued until the mouse made nine correct choices over 10 consecutive trials. When animals achieved this acquisition criterion, a probe trial was administered. In the probe trial, the previously unused fourth arm (North) was used as a stem arm. If the mice performed the probe trial correctly, response discrimination training was 

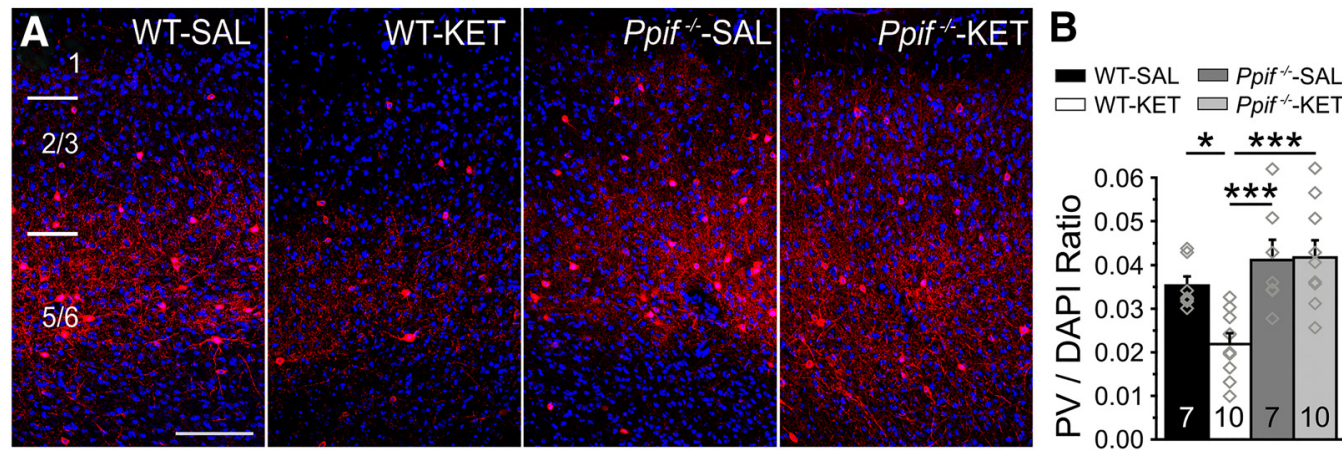

Figure 1. CypD deletion (Ppif-/-) protects against the loss of PV expression that results from perinatal KET treatment. WT or Ppif-/- mice received either saline (SAL) or KET injections on postnatal days 7, 9, and 11. $\boldsymbol{A}$, Representative confocal images of PV immunofluorescence (red) and DAPI (blue) from layers 1-6 of adult mPFC. $\boldsymbol{B}$, Total PV+ cells as a percentage of DAPI. Perinatal KET treatment significantly reduced PV expression in WT but not in Ppif- $/$ - mice. These experiments used 34 mice from 12 litters (two to four per treatment group). Significance is indicated as ${ }^{*} p \leq 0.05$ and ${ }^{* *} p \leq 0.001$, following Tukey correction. Scale bar in $A, 200 \mu \mathrm{m}$.

completed. If an incorrect turn occurred, response training continued until the mouse made another five consecutive correct choices, and then another probe trial was administered. On the next day (day 6, shift-to-visual-cue discrimination), mice were trained to shift their strategy to now select the choice arm with the visual cue to obtain food rewards. The location of the visual cue and the position of the start arm were again varied pseudorandomly so that their frequency was balanced across blocks of 12 consecutive trials. The training and response criteria for the shift-to-visual-cue discrimination were identical to those during response discrimination. For performance and error analysis, for each of the two test days, we analyzed the total number of trials to criterion and the number of probe trials required to reach criterion. For the shift-to-visual-cue discrimination, errors were scored as entries into arms that did not contain the visual cue, and they were further broken down into three subcategories to determine whether the animals' treatment altered the ability to either shift from the previously learned strategy (perseverative errors), or to maintain the new strategy after perseveration had ceased (regressive errors, or never-reinforced errors). In order to detect shifts in the strategies that animals used, trials were separated into consecutive blocks of four trials each. A perseverative error occurred when a mouse made the same egocentric response as required during the response discrimination, but which was opposite to the direction of the arm containing the visual cue. Six of every 12 consecutive trials required the mouse to respond in this manner. A perseverative error was scored when the mouse entered the incorrect arm on three or more trials per block of four trials. Once the mouse made less than three perseverative errors in a block, all subsequent errors of the same type were now scored as regressive errors (because at this point the mouse was following an alternative strategy at least half of the time). So-called never-reinforced errors were scored when a mouse entered the incorrect arm on trials where the visual cue was placed on the same side that the mouse had been trained to enter on the previous day.

\section{NOR}

Testing was conducted in a white wooden open chamber $(39 \times 19 \times$ $30.5 \mathrm{~cm}$ ), and sessions were recorded from above by a web camera for later analysis. Wooden toys $(\sim 3 \times 5 \mathrm{~cm})$ were used as stimulus objects and pseudorandomly selected as either the familiar or novel objects. In addition, in a different cohort of mice, object preference was measured before experiments to ensure mice showed no inherent preference across the objects used. Mice were first habituated for $10 \mathrm{~min}$ on two consecutive days to the empty chamber. On the third day, mice were again habituated for $10 \mathrm{~min}$ before the training and test trials begun. Therefore, mice were placed in their home cage while the chamber was cleaned and two objects were placed inside the chamber. Mice were then placed inside the chamber and allowed to investigate the two objects for $3 \mathrm{~min}$ before being placed back into the home cage for a 2-min intertrial interval during which one of the two familiar objects was replaced with a novel object. After $2 \mathrm{~min}$, mice were placed back into the chamber and allowed to explore both the familiar and novel object for an additional 2 min. The objects were cleaned with $20 \%$ ethanol, and the chamber was cleaned with $70 \%$ ethanol between animals. The amount of time the mice spent investigating the objects during both the training trial and the novel object trial was analyzed. In order to assess whether animals recognized the novel object as such, we calculated a "recognition index," which is the percentage of time spent investigating the novel object over the total investigation time for both objects.

\section{Social interaction}

Experimental mice and two size-matched and age-matched stimulus mice were housed individually for $3 \mathrm{~d}$ before the task. On the day of the test, the experimental mouse was placed into a new cage with $2.5 \mathrm{~g}$ of their original bedding material to allow the animal to habituate for $1 \mathrm{~h}$. Stimulus mice were kept in a small custom cylindrical holding apparatus (height $20 \mathrm{~cm}$, steel bars separated by $1 \mathrm{~cm}$, acrylic base, and lid), which could be placed inside the test cage. After $1 \mathrm{~h}$, the first stimulus mouse was placed in the holding apparatus and positioned into the cage with the test mouse for a trial interval of $1 \mathrm{~min}$ while being recorded by an overhead camera. This was repeated for four trials with an intertrial interval of $10 \mathrm{~min}$ (trials 1-4). On the fifth trial, a novel stimulus mouse was introduced into the cage to test for social recognition memory. All trials were recorded via an overhead camera and the interaction times (defined as sniffing and investigation of the stimulus mouse at close proximity) were analyzed for each trial.

\section{Statistical analysis}

Differences between groups were compared using one-way ANOVAs or two-way mixed ANOVAs as indicated. Post hoc analyses using Tukey correction were used to determine specific group differences. All data are presented as mean \pm SEM. An $\alpha$ level of $p<0.05$ was considered significant.

\section{Results}

\section{Perinatal KET treatment reduces PV expression in adult} $\mathrm{mPFC}$ in WT but not in Ppif-/- mice

A reduction in the number of PVIs is a hallmark of schizophrenia (Lewis et al., 2005; Nakazawa et al., 2012) that is recapitulated by most animal models, including perinatal KET application (Jeevakumar et al., 2015; Phensy et al., 2017a). To determine whether genetic deletion of CypD can protect against KETinduced reductions in PVI, we performed immunohistochemistry and quantified the number of $\mathrm{PV}+$ somata in the $\mathrm{mPFC}$ from both adult WT and Ppif-/- mice which received either KET or saline during development (Fig. 1). A one-way ANOVA revealed a main effect of treatment on the number of $\mathrm{PV}+$ cells over the number of DAPI+ cells $\left(F_{(3,30)}=8.990, p<0.001\right)$. WT KET-treated mice showed a significant loss in PV expression. In contrast, Ppif-/--KET mice were protected against KETinduced PVI loss and had similar numbers of PV + cells than saline-control mice (Fig. 1B). 

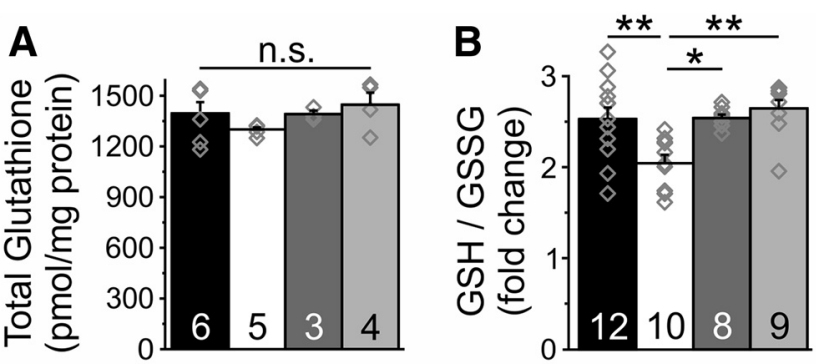

C

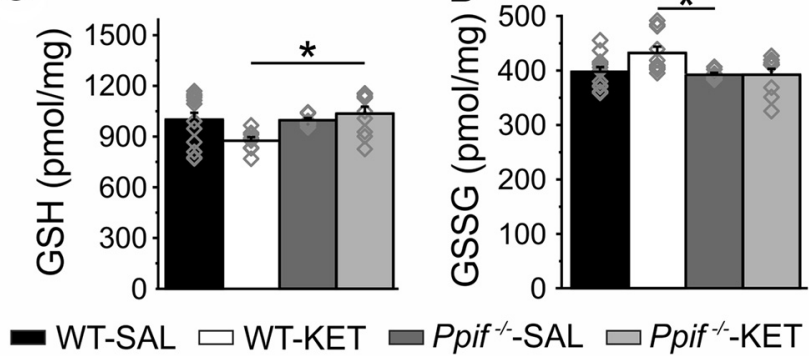

Figure 2. CypD deletion (Ppif-/-) reduces perinatal KET-induced oxidative stress in adult mPFC. $\boldsymbol{A}$, KET treatment does not affect total GSH levels. $\boldsymbol{B}$, KET treatment significantly reduces the ratio of the reduced (GSH) over oxidized (GSSG) form of GSH in WT mice, indicating increased oxidative stress. KET-treated Ppif-I- mice are protected from this shift in the GSH/GSSG ratio. $\boldsymbol{C}, \boldsymbol{D}$, Total levels of GSH $(\boldsymbol{C})$ and GSSG $(\boldsymbol{D})$ in adult mPFC tissue. Experiments used 18 animals (three to six per treatment group) from nine litters. Significance is indicated as ${ }^{*} p \leq 0.05$ and ${ }^{* *} p \leq 0.01$, following Tukey correction. n.s., not significant.

\section{KET-induced oxidative stress is reduced in Ppif-/ - mice}

Perinatal KET treatment leads to long-lasting increases in oxidative stress in adult animals, and PVIs are particularly sensitive to redox dysregulation (Do et al., 2009; Phensy et al., 2017a). The ratio between the bioavailable reduced $(\mathrm{GSH})$ and unavailable oxidized (GSSG) forms of the endogenous antioxidant GSH provides a measure of redox balance in cells. A decrease in this ratio indicates a disruption in redox balance and subsequent oxidative stress. To determine whether genetic deletion of CypD prevents KET-induced oxidative stress, we first measured levels of GSH and GSSG in mPFC tissue taken from adult mice (Fig. 2). A oneway ANOVA revealed that while there was no effect of treatment on total GSH levels $\left(F_{(3,14)}=1.172, p=0.3556\right.$; Fig. $\left.2 A\right)$, there was a main effect of treatment on the ratio of GSH/GSSG $\left(F_{(3,35)}\right.$ $=6.664, p=0.001$; Fig. $2 B$ ), with WT-KET mice having a significantly reduced GSH/GSSG ratio, indicating increased oxidative stress in these animals. A similar reduction was not observed in Ppif-/--KET mice. Next, we measured 4-HNE levels in PVIs of the mPFC (Fig. 3). 4-HNE levels increase during periods of oxidative stress due to lipid peroxidation. We colocalized immunofluorescence signals of 4-HNE and PV to measure changes in 4-HNE specifically in PVI. A one-way ANOVA revealed a main effect of treatment on the mean gray intensity of 4-HNE in PVI $\left(F_{(3,27)}=5.084, p=0.0064\right.$; Fig. $\left.3 B\right)$. This effect was due to a significant increase in 4-HNE signal in WT-KET mice, which was not present in Ppif-/--KET or saline-control mice. Taken together, these results show that PVIs in the mPFC of Ppif-/mice are protected from KET-induced oxidative stress.

Perinatal KET treatment alters inhibitory synaptic transmission onto layer 2/3 mPFC pyramidal cells in WT but not Ppif-/- mice

GABAergic PVIs inhibit nearby pyramidal neurons and regulate synchronized firing (Sohal and Rubenstein, 2019). Loss of PVI

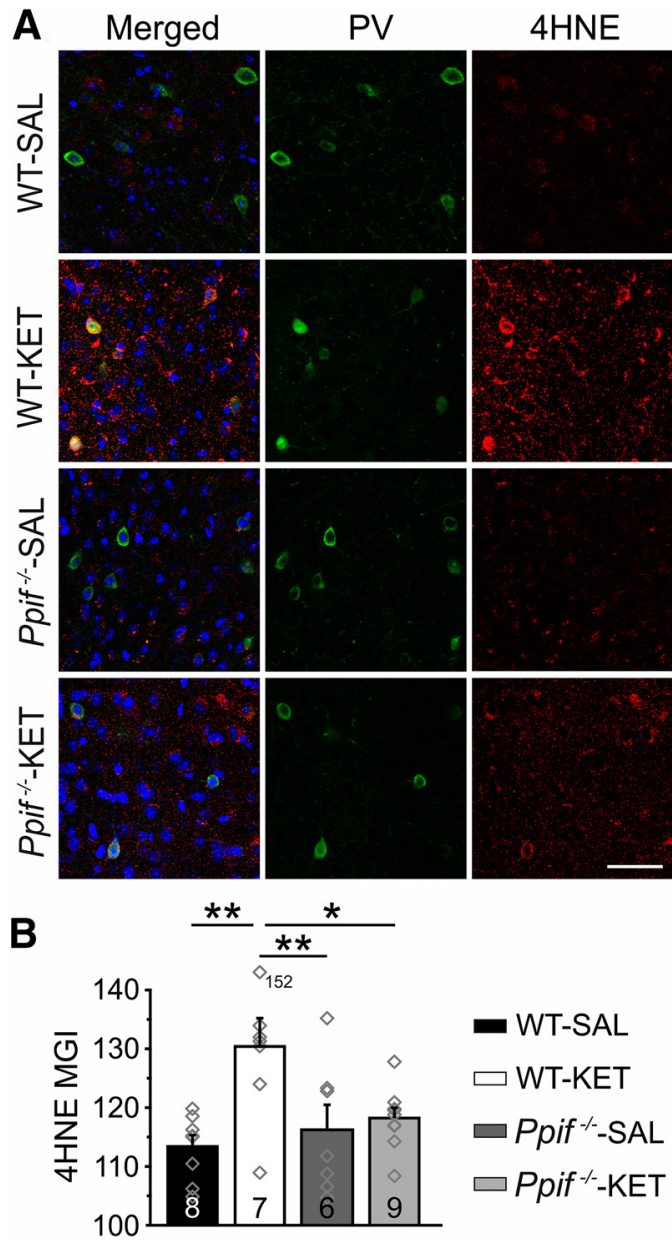

Figure 3. Perinatal KET treatment increases oxidative stress in PV+ interneurons (PVI) from WT but not from CypD knock-out (Ppif-/-) mice. $A$, Representative confocal images of PV (green) and 4-HNE (red) immunofluorescence in the MPFC. $\boldsymbol{B}$, PV cells in tissue from WT-KET mice had significantly higher levels of 4-HNE, a measure of lipid peroxidation and oxidative stress, than saline-treated WT mice (WT-SAL). KET-treated Ppif-/- mice were protected from this increase. Experiments used 31 mice from 11 litters (two to three per treatment group). Significance is indicated as ${ }^{*} p \leq 0.05$ and ${ }^{* *} p \leq 0.01$, following Tukey correction. Scale bar in $\boldsymbol{A}, 50 \mu \mathrm{m}$.

function leads to reduced GABAergic activity onto pyramidal neurons resulting in disinhibited circuits. In order to determine whether CypD deletion prevents KET-induced disinhibition of pyramidal cells, we performed whole-cell patch-clamp recordings in layer $2 / 3$ pyramidal neurons of the $\mathrm{MPFC}$ and quantified the frequency and amplitude of both sIPSCs and miniature IPSCs (mIPSCs; Fig. 4). We found a significant main effect of treatment on the frequency of mIPSCs $\left(F_{(3,28)}=6.547, p=0.002\right.$; Fig. $4 C)$, but no effect on amplitude $\left(F_{(3,28)}=1.689, p=0.192\right.$; Fig. 4C). Post hoc analyses revealed that this was driven by a selective decrease in mIPSC frequency in WT-KET mice. Similar changes did not occur in Ppif-/--KET or saline-control mice. KET treatment did not alter the frequency $\left(F_{(3,25)}=0.2440\right.$, $p=0.8648$; Fig. $4 F)$ or the amplitude $\left(F_{(3,25)}=0.1160, p=0.9499\right.$; Fig. $4 F$ ) of sIPSCs. These data suggest that KET reduces GABA release and that this can be prevented by CypD deletion.

KET treatment induces NMDAR hypofunction in layer 2/3 PVI from WT but not Ppif-/- mice NMDAR hypofunction likely contributes to aberrant network activity in schizophrenia (Snyder and Gao, 2013). Perinatal KET 
A

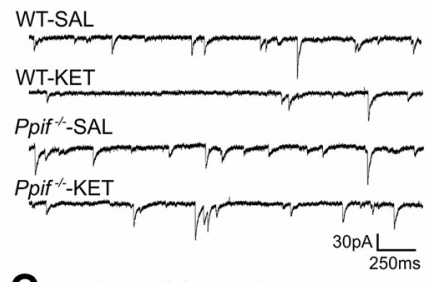

B

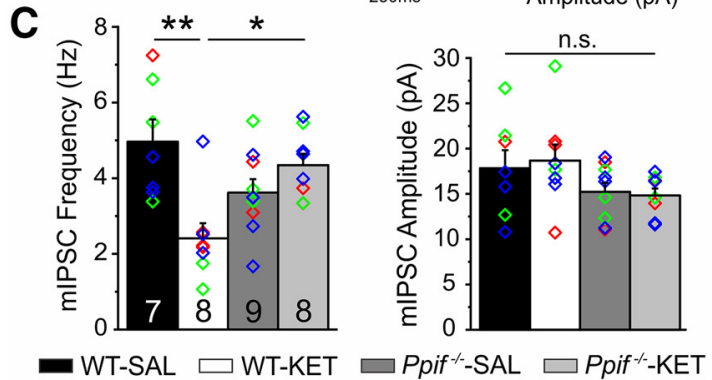

D

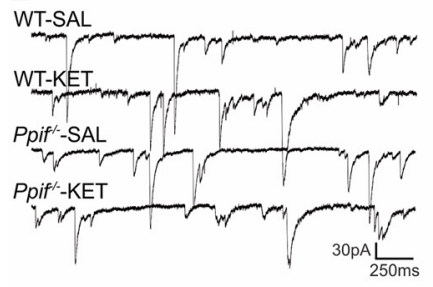

E

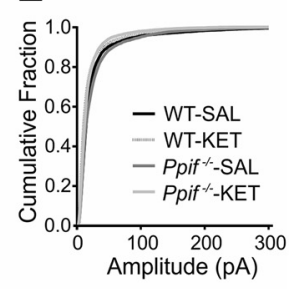

$\mathbf{F}$

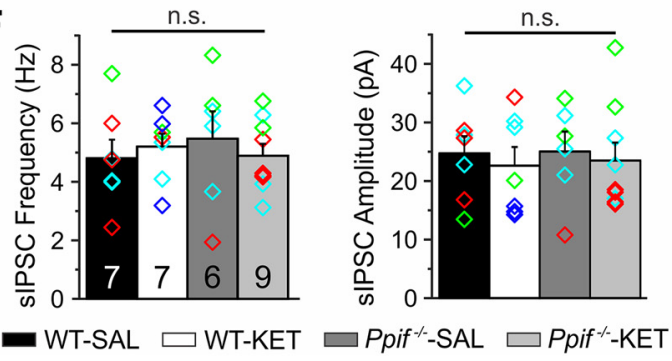

Figure 4. CypD deletion (Ppif-/-) protects against alterations in GABA release that develop in the mPFC following perinatal KET treatment. $A$, Representative traces of mIPSCs (in tetrodotoxin) recorded in layer $2 / 3$ pyramidal cells from in the four treatment groups. $\boldsymbol{B}$, Amplitude distribution of all mIPSC events in the four treatment groups. $C$, KET treatment significantly reduced the frequency, but not the amplitude, of mIPSCs onto layer $2 / 3$ pyramidal neurons from WT mice. Similar changes were not observed in Ppif-/_-KET mice. The numbers of cells are indicated in the bar graphs. Experiments used 12 animals (three per treatment group) from nine litters. Total events analyzed: 21,838. D, Representative traces of sIPSCs recorded in layer 2/3 pyramidal cells. $\boldsymbol{E}$, Amplitude distribution of all sIPSC events in the four treatment groups. $\boldsymbol{F}$, KET treatment did not alter the frequency or amplitude of sIPSCS. Experiments used 13 animals (three to four per treatment group) from eight litters. Total events analyzed: 26,328. Individual data points are shown as diamonds; colors indicate data from individual mice within a given group. Significance is indicated as ${ }^{*} p \leq 0.05$ and ${ }^{* *} p \leq 0.01$, following Tukey correction. n.s., not significant.

treatment disrupts PVI development in the mPFC, causing NMDAR hypofunction in adult layer 2/3 PVIs (Jeevakumar and Kroener, 2016; Phensy et al., 2017a). In order to test whether CypD deletion can prevent KET-induced changes in NMDAR signaling we next measured NMDAR and AMPAR currents in GFP + PVI (Fig. $5 A, B)$. A one-way ANOVA $\left(F_{(3,18)}=4.280\right.$, $p=0.019$; Fig. $5 B$ ) revealed a main effect of treatment on the ratio of NMDAR/AMPAR currents at layer 2/3 PVI. Consistent with our previous reports (Jeevakumar and Kroener, 2016; Phensy et al., 2017a), WT-KET mice had significantly reduced NMDAR/ AMPAR ratios. In contrast, Ppif-I--KET mice showed current ratios comparable to saline-treated controls, suggesting that genetic deletion of CypD offers protection from KET-induced aberrant NMDAR signaling in layer 2/3 PVI.

KET treatment alters spontaneous glutamate release onto layer 2/3 PVI from WT but not Ppif-/- mice

The KET-induced NMDAR hypofunction in layer 2/3 PVIs is accompanied by disinhibition of pyramidal cells (as seen in Fig. 4), which subsequently causes increased glutamate release back onto PVI (Jeevakumar and Kroener, 2016; Phensy et al., 2017a). The increased activation of postsynaptic glutamate receptors may lead to excessive calcium influx and contribute to persistent mitochondrial stress in PVI (Phensy et al., 2017a). To further test whether CypD deletion prevents KET-induced alterations in glutamatergic signaling at PVI, we recorded sEPSCs in GFP+ PVI (Fig. 5C,D). A one-way ANOVA revealed a main effect of treatment on sEPSC frequency $\left(F_{(3,23)}=5.812, p=0.004\right.$; Fig. $\left.5 D\right)$, without significant changes in sEPSC amplitude $\left(F_{(3,23)}=3.006\right.$, $p=0.051$; Fig. $5 D$ ). Consistent with the idea that mPFC pyramidal cells from KET-treated mice are disinhibited, post hoc analyses showed a selective increase in sEPSC frequency in PVI from WT-KET mice; a change that was not seen in any of the other treatment groups.

KET treatment induces deficits in cognitive flexibility, NOR, and social interactions in WT but not in Ppif-/- mice

In order to determine the functional impact of the physiological changes that result from KET treatment and CypD deletion, we tested adult mice in a battery of behavioral tasks. These tasks included a rule-shifting task to measure cognitive flexibility, a NOR task which measures (short-term) memory for objects, and a social interaction task which tests deficits in social interaction and novelty discrimination (Fig. 6; Jeevakumar et al., 2015; Phensy et al., 2017b).

\section{Rule-shifting task}

Cognitive flexibility is the ability to inhibit the use of a defunct strategy and enable the learning of a new functional strategy. The PFC is important for the ability to shift between strategies, and dysfunctions of the PFC lead to perseveration on inappropriate responses. To examine whether $\mathrm{CypD}$ deletion protects against KET-induced deficits in cognitive flexibility, we tested WT and Ppif-/- mice on a well-characterized rule-shifting task that is highly dependent on the mPFC (Birrell and Brown, 2000; Floresco and Magyar, 2006; Young et al., 2009; Hu et al., 2015; Jeevakumar and Kroener, 2016). Mice first learn an egocentric response discrimination strategy and then need to shift to a visual cue discrimination strategy. Mice in all treatment groups reached criterion for the response discrimination in the same number of trials $\left(F_{(3,26)}=0.4760, p=0.702\right.$; Fig. $\left.6 B\right)$. In contrast, a one-way ANOVA showed a main effect of treatment on the number of trials needed to reach criterion during the shift-to-visual-cue discrimination phase of the task $\left(F_{(3,26)}=9.576\right.$, $p<0.001$; Fig. $6 B$ ). WT-KET mice took significantly more trials to reach criterion compared with mice in all other treatment groups. To further differentiate the effects of KET treatment and CypD deletion on cognitive strategies, we analyzed the types of errors (perseverative, regressive, or never reinforced) that mice committed. A one-way ANOVA $\left(F_{(3,26)}=4.361, p=0.013\right.$; Fig. $6 C)$ revealed that KET treatment caused significantly more overall errors in WT, but not Ppif-/- or saline-control, mice. Furthermore, there was a significant effect of treatment on perseverative errors $\left(F_{(3,26)}=3.152, p=0.042\right.$; Fig. $\left.6 C\right)$ but not on regressive $\left(F_{(3,26)}=1.867, p=0.160\right.$; Fig. $\left.6 C\right)$, or never-reinforced 
A

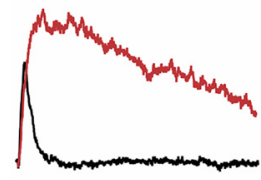

WT-SAL

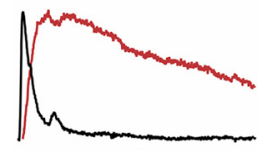

Ppif $^{-}$-SAL

C

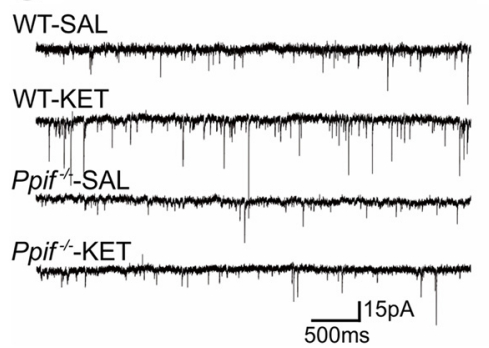

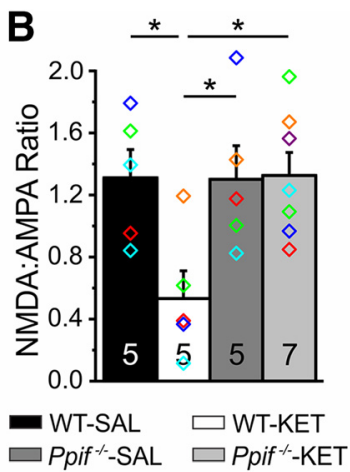

D

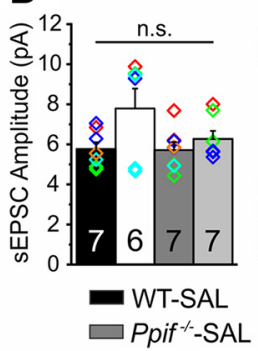

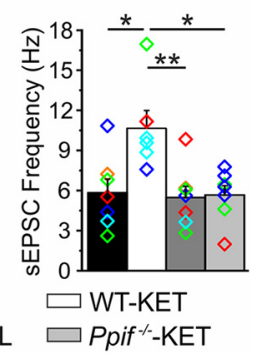

Figure 5. Perinatal KET treatment alters glutamatergic transmission onto layer $2 / 3 \mathrm{PV}+$ interneurons (PVI) in WT, but not in CypD knock-out (Ppif-/-), mice. A, Representative traces of NMDAR currents (red) and AMPAR (black) from GFP+ PVI neurons in layers $2 / 3$ of the mPFC. $B$, NMDAR/AMPAR ratios in the four treatment groups. KET-treated WT mice exhibit markedly decreased NMDAR/AMPAR ratios compared with saline (SAL)-treated mice, as well as KET-treated Ppif-/mice. For all recordings the numbers of cells are indicated in the bar graphs. Experiments used 20 animals (four to six per treatment group) from 16 litters. A minimum of 15 traces were averaged per recording. $C$, Representative traces of sEPSCS recorded at $-70 \mathrm{mV}$. D, KET treatment increased the frequency, but not the amplitude, of sEPSCs in WT mice, but not in Ppif- / - mice. Experiments used 15 animals (three to five per treatment group) from 11 litters. Total events analyzed: 28,303. Individual data points are shown as diamonds; colors indicate data from individual mice within a given group. Significance is indicated as ${ }^{*} p \leq 0.05$ and ${ }^{* *} p \leq 0.01$, following Tukey correction. n.s., not significant.

errors $\left(F_{(3,26)}=0.7296, p=0.544\right.$; Fig. $\left.6 C\right)$. The significant effect on perseverative errors was due to a selective increase in the WT-KET mice which was not observed in KET-treated Ppif-1or saline-control mice.

\section{NOR}

Mice, like humans, show preference for novel objects and spend more time investigating a novel object if they can correctly distinguish it from a previously encountered object. We next measured how KET treatment and CypD deletion affect NOR (Fig. $6 D-H)$. During the 3-min training phase, mice in all treatment groups exhibited comparable exploration times, suggesting that KET treatment does not impair general exploration $\left(F_{(3,31)}=\right.$ $0.344, p=0.794$; Fig. $6 E$ ). Following a 2 -min intertrial interval in which one of the two objects was replaced for a novel object, the mice were returned to the chamber and were allowed to explore the familiar and novel objects for an additional 2 min (test phase). We used a two-way mixed ANOVA to examine the effect of treatment and object-type (novel vs familiar) on investigation times during the test phase. We found a significant main effect of object-type $\left(F_{(1,31)}=52.69, p<0.001\right)$ and no main effect of treatment $\left(F_{(3,31)}=1.554, p=0.220\right.$; Fig. $\left.6 F\right)$ on overall investigation time. However, these main effects were qualified by a significant interaction between treatment and object-type $\left(F_{(3,31)}=\right.$ 4.460, $p=0.010)$. Bonferroni-adjusted comparisons indicated that while the majority of treatment groups exhibited preference for the novel object, WT-KET mice spent equal time investigating both objects (Fig. $6 \mathrm{G}$ ). To illustrate these differences further, we calculated a recognition index for each animal, which is the time spent investigating the novel object as a percent of total time investigating both objects. A one-way ANOVA across treatment groups $\left(F_{(3,31)}=\right.$ $6.375, p=0.002$; Fig. $6 H$ ) revealed a main effect of treatment on recognition index. WT-KET mice had reduced recognition indices; in contrast, Ppif-/--KET exhibited normal NOR and spent similar amounts of time as saline-controls investigating the novel object.

\section{Social interaction}

Deficits in social cognition and interaction greatly impact the quality of life of patients with schizophrenia. KET-treated mice show reduced social interactions (Jeevakumar et al., 2015; Phensy et al., 2017b). To test whether genetic deletion of CypD can prevent this social deficit, we performed a social interaction and recognition task (Fig. 6I). Mice initially show great interest anytime a new mouse is introduced into their home cage but gradually reduce their investigation time with repeated exposures (trials 1-4). This can be used to investigate differences in baseline social interaction and recognition memory when a new stimulus mouse is introduced into the cage (trial 5). A two-way mixed ANOVA revealed a significant main effect of treatment $\left(F_{(3,32)}=7.954, p<0.001\right.$; Fig. $\left.6 I\right)$ on social interaction. Consistent with our previous reports (Jeevakumar et al., 2015; Phensy et al., 2017b), WT-KET mice showed reduced investigation times across trials 1,2 , and 5 . In contrast, Ppif-/--KET mice demonstrated investigation times similar to saline-treated controls across all five exposures, suggesting normal social interaction and recognition memory.

\section{Discussion}

NMDAR dysfunction disrupts normal development of GABAergic and glutamatergic networks and this may contribute to schizophrenia pathology (Krystal et al., 2002). PVIs appear to be particularly susceptible to NMDAR dysfunction (Cohen et al., 2015), and changes in PVI, and their synapses are well documented in schizophrenia (Lewis et al., 2005; Nakazawa et al., 2012; Gonzalez-Burgos et al., 2015). PVIs are highly sensitive to oxidative stress (Do et al., 2009), which can disrupt neuronal function and decrease NMDAR activity (Choi and Lipton, 2000). Mitochondria are the primary mediators of redox state (Rego and Oliveira, 2003; Bhatti et al., 2017), and they are abundant in PVI (Gulyás et al., 2006); however, their role in PVI dysfunction has received relatively little attention. Oxidative and other cellular stresses trigger translocation of CypD to the inner mitochondrial membrane, initiating formation of the mPTP (Baines et al., 2005). Prolonged mPTP formation leads to excessive levels of intracellular superoxide and pathologic mitochondrial activity (Crompton, 2004; Lemasters et al., 2009). Glutamate excitotoxicity that results from overactivation of NMDARs and excessive calcium entry is a well- 
A

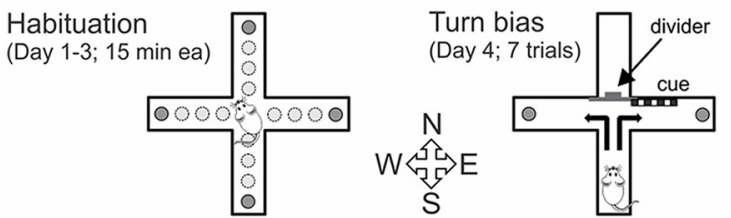

Response Discrimination (turn to one side, L or R; ignore cue)
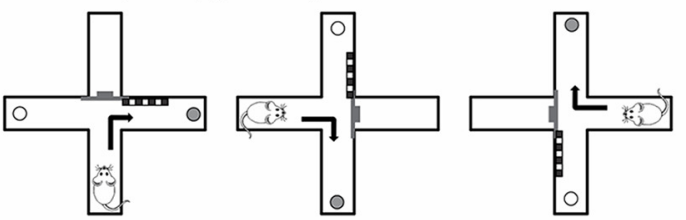

Shift-to-Visual-Cue (turn towards visual cue)
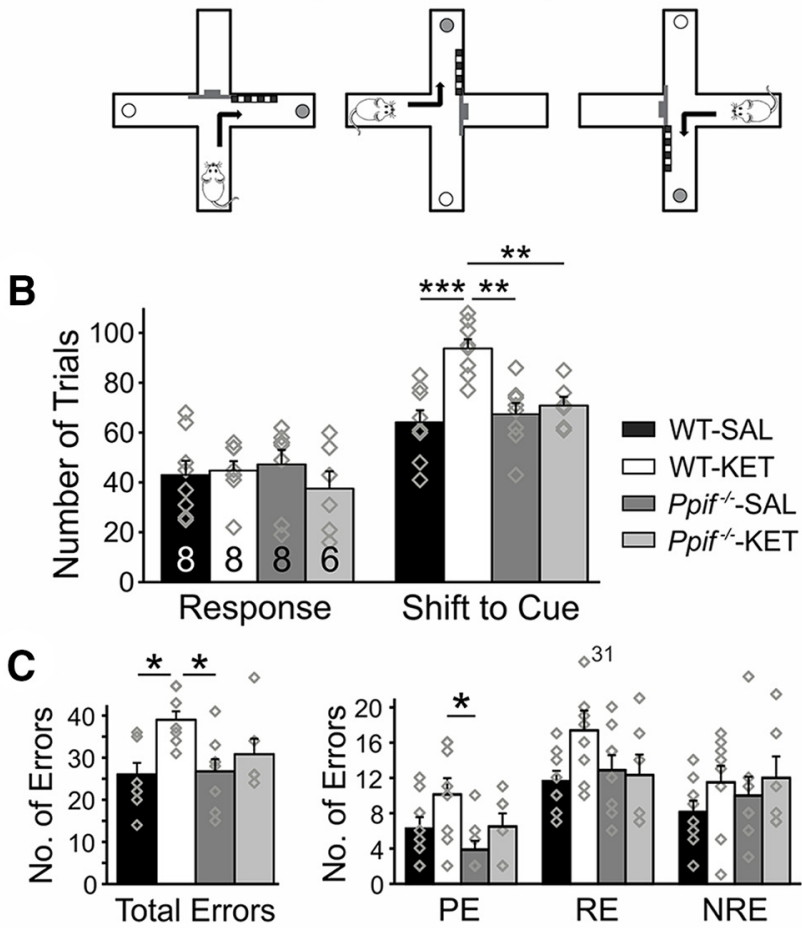

D
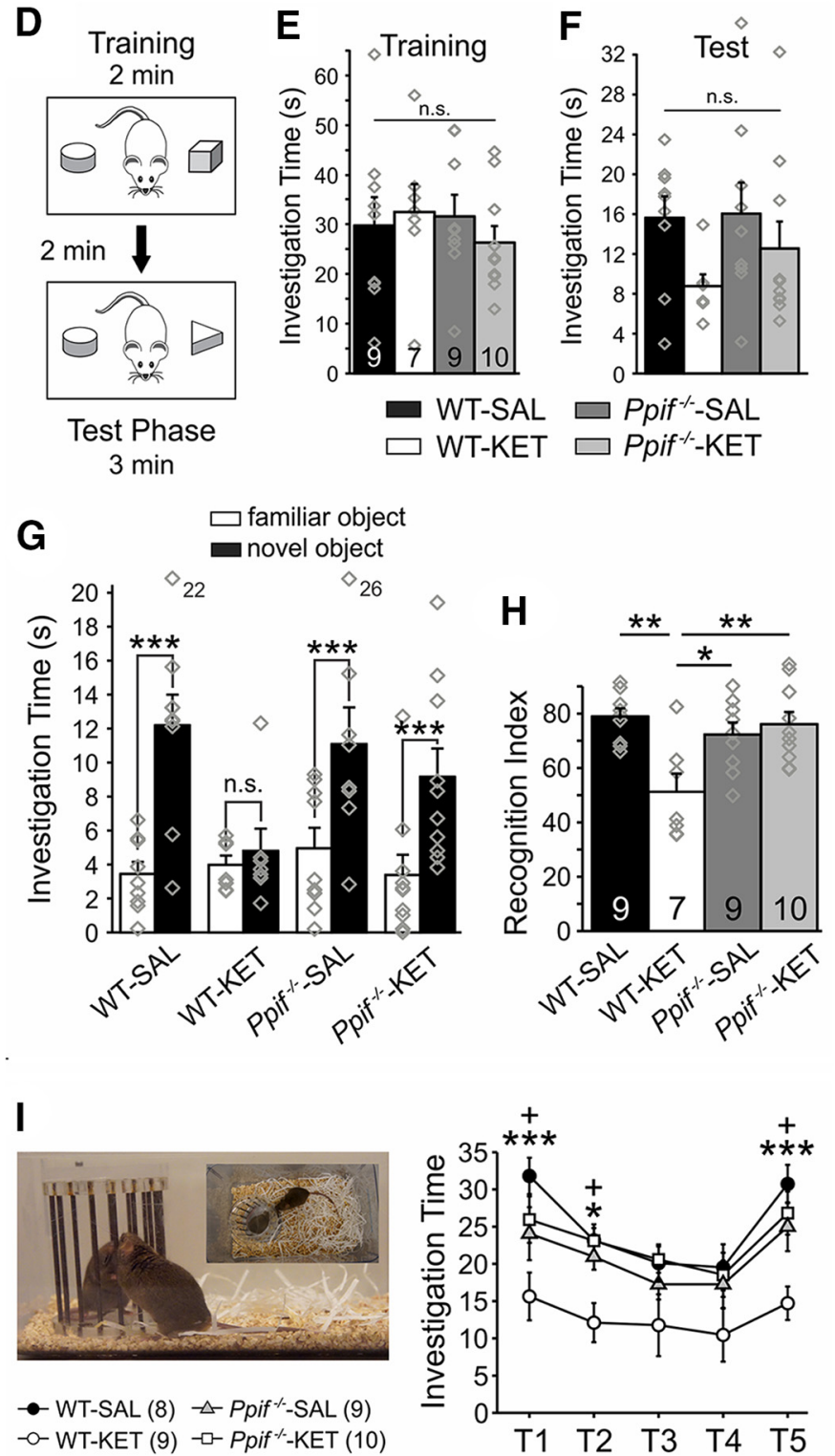

Figure 6. Perinatal KET treatment induced behavioral deficits in WT, but not in CypD knock-out, (Ppif-/-) mice. A, Schematic overview of the cross-maze rule-shifting task used to assess cognitive flexibility. Mice are first habituated over $3 \mathrm{~d}$ to a plus maze, and then, their turn bias is assessed on day 4. Mice then learn an egocentric strategy (response discrimination) to obtain a food reward and the next day are required to shift to a visual cue strategy (shift-to-visual-cue day). $\boldsymbol{B}$, All animals learned the initial response strategy at the same rate; however, WT-KET required a significantly larger number of trials to shift between strategies compared with saline-treated controls and KET-treated Ppif-/ - mice. C, Error analysis based on error types committed during the shift-to-cue session. WT-KET animals show an increase in total errors and a significantly higher number of perseverative errors. Experiments used 30 mice from 15 litters (three to four per treatment group). $\boldsymbol{D}$, Schematic overview of the setup used to test NOR. $\boldsymbol{E}, \boldsymbol{F}$, Mice in all groups showed comparable overall investigation times during the training phase and the test phase. $\mathbf{G}$, During the test phase, all treatment groups, with the exception of WT-KET mice, spent significantly more time investigating the novel object. $\boldsymbol{H}$, Recognition index indicating that KET treatment reduced NOR in WT, but not in Ppif- /-, mice. Experiments used 35 mice from nine litters (two to three per treatment group). $I$, Test of social interaction and recognition. A stimulus mouse is placed in the home cage of the test mouse for four 1-min sessions (10-min intertrial intervals), and social interaction time is recorded. On a fifth trial, a novel stimulus mouse is introduced to test social recognition. KET treatment results in reduced interaction times across all sessions. Ppif-/--KET mice patterns of social interaction comparable to saline-treated controls. Experiments used 33 mice from eight litters (two per treatment group). $\boldsymbol{B}, \boldsymbol{C}, \boldsymbol{H}$, Significance is indicated as ${ }^{*} p \leq 0.05,{ }^{* *} p \leq 0.01$, and ${ }^{* * *} p \leq 0.001$, following Tukey correction. $\boldsymbol{G}$, Significance is indicated as ${ }^{* * *} p \leq 0.001$, following Bonferroni correction. $I$, Significance is indicated as ${ }^{*} p \leq 0.05$ WT-SAL versus WT-KET, ${ }^{* * *} p \leq 0.001$ WT-SAL versus WT-KET, and $+p \leq 0.05$ for WT-KET versus Ppif-/--KET following Tukey correction. n.S., not significant.

established initiator of chronic MPTP formation (Schinder et al., 1996).

NMDAR blockade disrupts development of PVIs, alters E/I balance, and impairs cognitive performance (Wang et al., 2008; Jeevakumar and Kroener, 2016). There is strong evidence that these changes are mediated by oxidative stress (Radonjić et al., 2010; Powell et al., 2012), and we previously demonstrated that boosting antioxidant defense systems with $\mathrm{N}$-acetyl cysteine can counter the physiological and behavioral deficits induced by perinatal KET treatment (Phensy et al., 2017a). We also found that perinatal KET treatment significantly increased levels of mitochondrial-derived ROS and reduced mitochondrial membrane potentials in PVIs. These changes are signs of prolonged mPTP activation, suggesting mitochondria as important nodes in KETinduced PVI dysfunction. CypD is a necessary component of the $\mathrm{mPTP}$, and reducing CypD translocation protects mitochondrial 
function (Du and Yan, 2010). Thus, we hypothesized that Ppif-/- mice would be protected from KET-induced increases in oxidative stress and PVI dysfunction.

We measured GSH levels to determine the redox state of PFC tissue from adult KET-treated and SAL-treated mice. The ratio of GSH to GSSG indicates cell redox status, with healthy cells having a large GSH/GSSG ratio, that drops when they get exposed to oxidative stress (Pizzorno, 2014). WT KET-treated mice showed a significant decrease in the GSH/GSSG ratio in PFC. This is in line with previous findings by us (Phensy et al., 2017a) and others (Powell et al., 2012), which have shown that NMDAR blockade during development drives oxidative stress in the frontal cortex. We also found increased levels of 4-HNE, a by-product of lipid peroxidation, in prefrontal PVI of WT-KET mice. Lipid peroxidation occurs when free radicals damage lipids, and it is an indicator of the damage that results from oxidative stress. Ppif-/--KET mice demonstrated robust protection against KET-induced reductions in the GSH/GSSG ratio and the increase of 4-HNE levels in PVI (Figs. 2, 3). Because Ppif-/--KET mice also showed no significant loss of $\mathrm{PV}$ immunofluorescence in the PFC, these results support the idea that PVI dysfunction results from mitochondrial oxidative stress. Previous reports have shown that PVI dysfunction following perinatal NMDAR blockade requires activation of NADPH-oxidase 2 (NOX2) (Behrens et al., 2007; Sorce et al., 2010). Interestingly, there is evidence for significant cross talk between mitochondria and NOX2, which can reciprocally drive ROS production (Dikalov, 2011; Daiber et al., 2017). Thus, our data support these studies and suggest a complementary mechanism to NOX2-mediated PVI deficits.

NMDAR hypofunction in PVI is believed to contribute to aberrant synaptic activity in schizophrenia (Homayoun and Moghaddam, 2007). NMDARs can be directly inhibited by oxidizing agents via interaction on a redox-sensitive site on the receptor (Choi and Lipton, 2000). Developmental NMDAR blockade with KET leads to both long-lasting increases in oxidative stress and NMDAR hypofunction in layer $2 / 3$ prefrontal PVIs (Phensy et al., 2017a). Because Ppif-/--KET mice exhibited reduced signs of oxidative stress, we investigated whether this was accompanied by normal NMDAR function in layer $2 / 3$ PVIs. Consistent with our previous findings (Jeevakumar and Kroener, 2016; Phensy et al., 2017a), PVI in layers 2/3 from KET-treated WT mice showed reduced NMDAR currents. In contrast, Ppif-/--KET mice exhibited normal NMDAR/ AMPAR current ratios (Fig. 4). Because KET treatment did not affect amplitudes of AMPA-mediated sEPSCs, this effect of CypD deletion most likely represents a selective protection of NMDAR function. Reduced NMDAR activity has significant implications for PVI function. Gating of NMDARs causes influx of calcium which can help in persistent neuronal firing (Myme et al., 2003), an important feature of PVI physiology. Blocking NMDAR on PVI has been shown to impair the generation of $\gamma$ oscillations (Jadi et al., 2016), which are crucial to cognitive function (Fries, 2009; Sohal et al., 2009). Perturbations in $\gamma$ oscillations are believed to result from reduced PVI activity and a shift in the E/I balance (Gonzalez-Burgos et al., 2015; Sohal and Rubenstein, 2019). Consistent with the idea of a shift in the E/I balance, KET treatment in WT mice lead to a long-lasting reduction in GABAergic inhibition at pyramidal neurons and increased glutamate release back onto layer 2/3 PVIs. In contrast, in addition to preserved NMDAR function in PVIs, Ppif-/mice exhibited normal sEPSCs and mIPSCs in PVIs and pyramidal cells, respectively, suggesting that normal E/I balance in the mPFC network was maintained.

Patients with schizophrenia suffer from a number of PFC-dependent cognitive deficits including disruptions in working memory, social cognition, attention, and cognitive flexibility (Braff et al., 1991; Gold et al., 1997; Nuechterlein et al., 2004). Evidence from clinical and preclinical models suggests that NMDAR hypofunction contributes to these deficits (Coyle, 2012; Cohen et al., 2015): NMDAR blockade can reduce cognitive abilities in healthy patients and exacerbate deficits in schizophrenia patients (Lahti et al., 1995; Malhotra et al., 1997; Krystal et al., 2002), and it impairs cognitive flexibility, episodic memory, and social interactions in rodents (Stefani and Moghaddam, 2005; Powell et al., 2012; Jeevakumar et al., 2015). In order to determine whether CypD deletion also protects against KET-induced cognitive deficits, we examined the performance of Ppif-/--KET mice in a variety of tasks (Fig. 6). In rodents, cognitive flexibility is most often assessed via attentional set-shifting tasks (Young et al., 2012). Here, we measured cognitive flexibility through a ruleshifting task, which requires only a simple shift from an egocentric response strategy to a visual cue-based strategy (Stefani and Moghaddam, 2005; Floresco et al., 2006). Consistent with previous findings (Stefani and Moghaddam, 2005; Broberg et al., 2008; Jeevakumar et al., 2015), we found that WT-KET mice required more trials to shift their strategies and committed a larger number of perseverative errors (Fig. 6A-C). Perseverative errors suggest an inability to abandon a defunct strategy, a deficit that is frequently observed in patients with schizophrenia (Abbruzzese et al., 1996) or lesions of the PFC (Barceló and Knight, 2002). Patients with schizophrenia also suffer from deficits in episodic memory (Ragland et al., 2009). In rodents, episodic memory can be assessed via the NOR task. Performance on the task relies heavily on interactions between PFC and hippocampal circuits (Korotkova et al., 2010), which are disrupted by blockade (Jadi et al., 2016) or ablation (Korotkova et al., 2010) of NMDARs. Both acute (Rajagopal et al., 2014) and developmental (Jeevakumar et al., 2015; Phensy et al., 2017b) KET treatment results in reduced NOR. Finally, we examined changes in social interaction in KETtreated WT and Ppif-/- animals. Reduced social interactions and isolation are negative symptoms associated with schizophrenia (Millan et al., 2014; Green et al., 2015). Consistent with what we (Phensy et al., 2017b) and others (Powell et al., 2012) have previously shown, developmental NMDAR blockade in WT mice reduced social interaction times across all presentations of the stimulus mice. Importantly, Ppif-/- mice showed robust protection against all KET-induced behavioral deficits. These findings strongly suggest that transient NMDAR blockade affects cortical networks and behavior via processes that depend on proper mitochondrial function and that modulation of the mPTP via genetic deletion of CypD can prevent these effects. These findings are in line with a number of other studies in which genetic deletion or pharmacological inhibition of CypD has been shown to offer protection against cognitive dysfunction in other preclinical disease models (Du et al., 2008; Yan et al., 2016; Nusrat et al., 2018). One previous study reported higher indices of anxiety and a reduced tendency to explore in Ppif-/mice (Luvisetto et al., 2008); however, we did not find evidence for reduced exploration during NOR or the cross-maze ruleshifting task, nor did we observe any other unspecific phenotypical changes in Ppif-/- mice.

Taken together, our results underscore the impact of mitochondria on cortical networks and cognition. Mitochondria not only play essential roles in cell function, but their bioenergetics 
are crucial for proper neuronal development (Cobley, 2018), and even acute dysfunction impairs learning and memory (Mancini and Horvath, 2017). Here, we illustrate how CypD activity can drive mitochondrial dysfunction in PVI and show that CypD may be a potential therapeutic target in protecting cognitive function in schizophrenia.

\section{References}

Abbruzzese M, Ferri S, Scarone S (1996) Performance on the Wisconsin card sorting test in schizophrenia: perseveration in clinical subtypes. Psychiatry Res 64:27-33.

Abekawa T, Ito K, Nakagawa S, Koyama T (2007) Prenatal exposure to an NMDA receptor antagonist, MK-801 reduces density of parvalbumin-immunoreactive GABAergic neurons in the medial prefrontal cortex and enhances phencyclidine-induced hyperlocomotion but not behavioral sensitization to methamphetamine in postpubertal rats. Psychopharmacology (Berl) 192:303-316.

Akbarian S, Huang HS (2006) Molecular and cellular mechanisms of altered GAD1/GAD67 expression in schizophrenia and related disorders. Brain Res Rev 52:293-304.

Altar CA, Jurata LW, Charles V, Lemire A, Liu P, Bukhman Y, Young TA, Bullard J, Yokoe H, Webster MJ, Knable MB, Brockman JA (2005) Deficient hippocampal neuron expression of proteasome, ubiquitin, and mitochondrial genes in multiple schizophrenia cohorts. Biol Psychiatry 58:85-96.

Anticevic A, Gancsos M, Murray JD, Repovs G, Driesen NR, Ennis DJ, Niciu MJ, Morgan PT, Surti TS, Bloch MH, Ramani R, Smith MA, Wang XJ, Krystal JH, Corlett PR (2012) NMDA receptor function in large-scale anticorrelated neural systems with implications for cognition and schizophrenia. Proc Natl Acad Sci USA 109:16720-16725.

Baines CP, Kaiser RA, Purcell NH, Blair NS, Osinska H, Hambleton MA, Brunskill EW, Sayen MR, Gottlieb RA, Dorn GW, Robbins J, Molkentin JD (2005) Loss of cyclophilin D reveals a critical role for mitochondrial permeability transition in cell death. Nature 434:658-662.

Barceló F, Knight RT (2002) Both random and perseverative errors underlie WCST deficits in prefrontal patients. Neuropsychologia 40:349-356.

Basso E, Fante L, Fowlkes J, Petronilli V, Forte MA, Bernardi P (2005) Properties of the permeability transition pore in mitochondria devoid of cyclophilin D. J Biol Chem 280:18558-18561.

Behrens MM, Ali SS, Dao DN, Lucero J, Shekhtman G, Quick KL, Dugan LL (2007) Ketamine-induced loss of phenotype of fast-spiking interneurons is mediated by NADPH-oxidase. Science 318:1645-1647.

Belforte JE, Zsiros V, Sklar ER, Jiang Z, Yu G, Li Y, Quinlan EM, Nakazawa K (2010) Postnatal NMDA receptor ablation in corticolimbic interneurons confers schizophrenia-like phenotypes. Nat Neurosci 13:76-83.

Ben-Shachar D, Laifenfeld D (2004) Mitochondria, synaptic plasticity, and schizophrenia. Int Rev Neurobiol 59:273-296.

Bhatti JS, Bhatti GK, Reddy PH (2017) Mitochondrial dysfunction and oxidative stress in metabolic disorders - A step towards mitochondria based therapeutic strategies. Biochim Biophys Acta Mol Basis Dis 1863:10661077.

Birnbaum R, Jaffe AE, Chen Q, Hyde TM, Kleinman JE, Weinberger DR (2015) Investigation of the prenatal expression patterns of 108 schizophrenia-associated genetic loci. Biol Psychiatry 77:e43-e51.

Birrell JM, Brown VJ (2000) Medial frontal cortex mediates perceptual attentional set shifting in the rat. J Neurosci 20:4320-4324.

Braff DL, Heaton R, Kuck J, Cullum M, Moranville J, Grant I, Zisook S (1991) The generalized pattern of neuropsychological deficits in outpatients with chronic schizophrenia with heterogeneous Wisconsin card sorting test results. Arch Gen Psychiatry 48:891-898.

Braun I, Genius J, Grunze H, Bender A, Möller HJ, Rujescu D (2007) Alterations of hippocampal and prefrontal GABAergic interneurons in an animal model of psychosis induced by NMDA receptor antagonism. Schizophr Res 97:254-263.

Broberg BV, Dias R, Glenthøj BY, Olsen CK (2008) Evaluation of a neurodevelopmental model of schizophrenia-early postnatal PCP treatment in attentional set-shifting. Behav Brain Res 190:160-163.

Catts VS, Fung SJ, Long LE, Joshi D, Vercammen A, Allen KM, Fillman SG, Rothmond DA, Sinclair D, Tiwari Y, Tsai SY, Weickert TW, Shannon Weickert C (2013) Rethinking schizophrenia in the context of normal neurodevelopment. Front Cell Neurosci 7:60.
Chen Q, Vazquez EJ, Moghaddas S, Hoppel CL, Lesnefsky EJ (2003) Production of reactive oxygen species by mitochondria: central role of complex III. J Biol Chem 278:36027-36031.

Choi YB, Lipton SA (2000) Redox modulation of the NMDA receptor. Cell Mol Life Sci 57:1535-1541.

Cobley JN (2018) Synapse pruning: mitochondrial ROS with their hands on the shears. Bioessays 40:e1800031.

Cohen SM, Tsien RW, Goff DC, Halassa MM (2015) The impact of NMDA receptor hypofunction on GABAergic neurons in the pathophysiology of schizophrenia. Schizophr Res 167:98-107.

Connern CP, Halestrap AP (1994) Recruitment of mitochondrial cyclophilin to the mitochondrial inner membrane under conditions of oxidative stress that enhance the opening of a calcium-sensitive non-specific channel. Biochem J 302:321-324.

Coyle JT (2012) NMDA receptor and schizophrenia: a brief history. Schizophr Bull 38:920-926.

Crompton M (2004) Mitochondria and aging: a role for the permeability transition? Aging Cell 3:3-6.

Cruz-Aguado R, Francis-Turner L, Díaz-Suárez CM, Bergado J (1999) NGF prevents changes in rat brain glutathione-related enzymes following transection of the septohippocampal pathway. Neurochem Int 34:125130

Daiber A, Di Lisa F, Oelze M, Kröller-Schön S, Steven S, Schulz E, Münzel T (2017) Crosstalk of mitochondria with NADPH oxidase via reactive oxygen and nitrogen species signalling and its role for vascular function. $\mathrm{Br} \mathrm{J}$ Pharmacol 174:1670-1689.

Dikalov S (2011) Cross talk between mitochondria and NADPH oxidases. Free Radic Biol Med 51:1289-1301.

Do KQ, Cabungcal JH, Frank A, Steullet P, Cuenod M (2009) Redox dysregulation, neurodevelopment, and schizophrenia. Curr Opin Neurobiol 19:220-230.

$\mathrm{Du}$ H, Yan SS (2010) Mitochondrial medicine for neurodegenerative diseases. Int J Biochem Cell Biol 42:560-572.

Du H, Guo L, Fang F, Chen D, Sosunov AA, McKhann GM, Yan Y, Wang C, Zhang H, Molkentin JD, Gunn-Moore FJ, Vonsattel JP, Arancio O, Chen JX, Yan SD (2008) Cyclophilin D deficiency attenuates mitochondrial and neuronal perturbation and ameliorates learning and memory in Alzheimer's disease. Nat Med 14:1097-1105.

Floresco SB, Magyar O (2006) Mesocortical dopamine modulation of executive functions: beyond working memory. Psychopharmacology (Berl) 188:567-585.

Floresco SB, Ghods-Sharifi S, Vexelman C, Magyar O (2006) Dissociable roles for the nucleus accumbens core and shell in regulating set shifting. J Neurosci 26:2449-2457.

Fries P (2009) Neuronal gamma-band synchronization as a fundamental process in cortical computation. Annu Rev Neurosci 32:209-224.

Gold JM, Carpenter C, Randolph C, Goldberg TE, Weinberger DR (1997) Auditory working memory and Wisconsin card sorting test performance in schizophrenia. Arch Gen Psychiatry 54:159-165.

Gonzalez-Burgos G, Cho RY, Lewis DA (2015) Alterations in cortical network oscillations and parvalbumin neurons in schizophrenia. Biol Psychiatry 77:1031-1040.

Green MF, Horan WP, Lee J (2015) Social cognition in schizophrenia. Nat Rev Neurosci 16:620-631.

Gulsuner S, Walsh T, Watts AC, Lee MK, Thornton AM, Casadei S, Rippey C, Shahin H; Consortium on the Genetics of Schizophrenia (COGS); PAARTNERS Study Group, Nimgaonkar VL, Go RC, Savage RM, Swerdlow NR, Gur RE, Braff DL, King MC, McClellan JM (2013) Spatial and temporal mapping of de novo mutations in schizophrenia to a fetal prefrontal cortical network. Cell 154:518-529.

Gulyás AI, Buzsáki G, Freund TF, Hirase H (2006) Populations of hippocampal inhibitory neurons express different levels of cytochrome $c$. Eur J Neurosci 23:2581-2594.

Halestrap AP (2010) A pore way to die: the role of mitochondria in reperfusion injury and cardioprotection. Biochem Soc Trans 38:841-860.

Hardingham GE, Do KQ (2016) Linking early-life NMDAR hypofunction and oxidative stress in schizophrenia pathogenesis. Nat Rev Neurosci 17:125-134.

Harrison PJ, Owen MJ (2003) Genes for schizophrenia? Recent findings and their pathophysiological implications. Lancet 361:417-419.

Hjelm BE, Rollins B, Mamdani F, Lauterborn JC, Kirov G, Lynch G, Gall CM, Sequeira A, Vawter MP (2015) Evidence of mitochondrial 
dysfunction within the complex genetic etiology of schizophrenia. Mol Neuropsychiatry 1:201-219.

Homayoun H, Moghaddam B (2007) NMDA receptor hypofunction produces opposite effects on prefrontal cortex interneurons and pyramidal neurons. J Neurosci 27:11496-11500.

Hong IS, Lee HY, Kim HP (2014) Anti-oxidative effects of Rooibos tea (Aspalathus linearis) on immobilization-induced oxidative stress in rat brain. PLoS One 9:e87061.

Hu W, Morris B, Carrasco A, Kroener S (2015) Effects of acamprosate on attentional set-shifting and cellular function in the prefrontal cortex of chronic alcohol-exposed mice. Alcohol Clin Exp Res 39:953-961.

Insel TR (2010) Rethinking schizophrenia. Nature 468:187-193.

Iwamoto K, Bundo M, Kato T (2005) Altered expression of mitochondriarelated genes in postmortem brains of patients with bipolar disorder or schizophrenia, as revealed by large-scale DNA microarray analysis. Hum Mol Genet 14:241-253.

Jadi MP, Behrens MM, Sejnowski TJ (2016) Abnormal gamma oscillations in $\mathrm{N}$-methyl-D-aspartate receptor hypofunction models of schizophrenia. Biol Psychiatry 79:716-726.

Jeevakumar V, Kroener S (2016) Ketamine administration during the second postnatal week alters synaptic properties of fast-spiking interneurons in the medial prefrontal cortex of adult mice. Cereb Cortex 26:1117-1129.

Jeevakumar V, Driskill C, Paine A, Sobhanian M, Vakil H, Morris B, Ramos J, Kroener S (2015) Ketamine administration during the second postnatal week induces enduring schizophrenia-like behavioral symptoms and reduces parvalbumin expression in the medial prefrontal cortex of adult mice. Behav Brain Res 282:165-175.

Jiang Z, Cowell RM, Nakazawa K (2013) Convergence of genetic and environmental factors on parvalbumin-positive interneurons in schizophrenia. Front Behav Neurosci 7:116.

Kann O, Kovács R (2007) Mitochondria and neuronal activity. Am J Physiol, Cell Physiol 292:C641-C657.

Korotkova T, Fuchs EC, Ponomarenko A, von Engelhardt J, Monyer H (2010) NMDA receptor ablation on parvalbumin-positive interneurons impairs hippocampal synchrony, spatial representations, and working memory. Neuron 68:557-569.

Krystal JH, Anand A, Moghaddam B (2002) Effects of NMDA receptor antagonists: implications for the pathophysiology of schizophrenia. Arch Gen Psychiatry 59:663-664.

Lahti AC, Koffel B, LaPorte D, Tamminga CA (1995) Subanesthetic doses of ketamine stimulate psychosis in schizophrenia. Neuropsychopharmacology 13:9-19.

Lemasters JJ, Theruvath TP, Zhong Z, Nieminen AL (2009) Mitochondrial calcium and the permeability transition in cell death. Biochim Biophys Acta 1787:1395-1401.

Lewis DA, Hashimoto T, Volk DW (2005) Cortical inhibitory neurons and schizophrenia. Nat Rev Neurosci 6:312-324.

Lewis DA, Curley AA, Glausier JR, Volk DW (2012) Cortical parvalbumin interneurons and cognitive dysfunction in schizophrenia. Trends Neurosci 35:57-67.

Li Z, Okamoto K, Hayashi Y, Sheng M (2004) The importance of dendritic mitochondria in the morphogenesis and plasticity of spines and synapses. Cell 119:873-887.

Lipton JW, Gyawali S, Borys ED, Koprich JB, Ptaszny M, McGuire SO (2003) Prenatal cocaine administration increases glutathione and alpha-tocopherol oxidation in fetal rat brain. Brain Res Dev Brain Res 147:77-84.

Luvisetto S, Basso E, Petronilli V, Bernardi P, Forte M (2008) Enhancement of anxiety, facilitation of avoidance behavior, and occurrence of adultonset obesity in mice lacking mitochondrial cyclophilin D. Neuroscience 155:585-596.

Malhotra AK, Pinals DA, Adler CM, Elman I, Clifton A, Pickar D, Breier A (1997) Ketamine-induced exacerbation of psychotic symptoms and cognitive impairment in neuroleptic-free schizophrenics. Neuropsychopharmacology 17:141-150.

Mancini G, Horvath TL (2017) Mitochondria bioenergetic and cognitive functions: the cannabinoid Link. Trends Cell Biol 27:391-392.

Millan MJ, Fone K, Steckler T, Horan WP (2014) Negative symptoms of schizophrenia: clinical characteristics, pathophysiological substrates, experimental models and prospects for improved treatment. Eur Neuropsychopharmacol 24:645-692.
Myme CI, Sugino K, Turrigiano GG, Nelson SB (2003) The NMDA-toAMPA ratio at synapses onto layer $2 / 3$ pyramidal neurons is conserved across prefrontal and visual cortices. J Neurophysiol 90:771-779.

Nakazawa K, Zsiros V, Jiang Z, Nakao K, Kolata S, Zhang S, Belforte JE (2012) GABAergic interneuron origin of schizophrenia pathophysiology. Neuropharmacology 62:1574-1583.

Nuechterlein KH, Barch DM, Gold JM, Goldberg TE, Green MF, Heaton RK (2004) Identification of separable cognitive factors in schizophrenia. Schizophr Res 72:29-39.

Nusrat L, Livingston-Thomas JM, Raguthevan V, Adams K, Vonderwalde I, Corbett D, Morshead CM (2018) Cyclosporin A-mediated activation of endogenous neural precursor cells promotes cognitive recovery in a mouse model of stroke. Front Aging Neurosci 10:93.

Olney JW, Newcomer JW, Farber NB (1999) NMDA receptor hypofunction model of schizophrenia. J Psychiatr Res 33:523-533.

Pers TH, Timshel P, Ripke S, Lent S, Sullivan PF, O'Donovan MC, Franke L, Hirschhorn JN; Schizophrenia Working Group of the Psychiatric Genomics Consortium (2016) Comprehensive analysis of schizophreniaassociated loci highlights ion channel pathways and biologically plausible candidate causal genes. Hum Mol Genet 25:1247-1254.

Phensy A, Driskill C, Lindquist K, Guo L, Jeevakumar V, Fowler B, Du H, Kroener S (2017a) Antioxidant treatment in male mice prevents mitochondrial and synaptic changes in an NMDA receptor dysfunction model of schizophrenia. eNeuro 4:ENEURO.0081-17.2017.

Phensy A, Duzdabanian HE, Brewer S, Panjabi A, Driskill C, Berz A, Peng G, Kroener S (2017b) Antioxidant treatment with $\mathrm{N}$-acetyl cysteine prevents the development of cognitive and social behavioral deficits that result from perinatal ketamine treatment. Front Behav Neurosci 11:106.

Pizzorno J (2014) Glutathione! Integr Med (Encinitas) 13:8-12.

Plitman E, Nakajima S, de la Fuente-Sandoval C, Gerretsen P, Chakravarty MM, Kobylianskii J, Chung JK, Caravaggio F, Iwata Y, Remington G, Graff-Guerrero A (2014) Glutamate-mediated excitotoxicity in schizophrenia: a review. Eur Neuropsychopharmacol 24:1591-1605.

Pocklington AJ, Rees E, Walters JT, Han J, Kavanagh DH, Chambert KD, Holmans P, Moran JL, McCarroll SA, Kirov G, O'Donovan MC, Owen MJ (2015) Novel findings from CNVs implicate inhibitory and excitatory signaling complexes in schizophrenia. Neuron 86:1203-1214.

Powell SB, Sejnowski TJ, Behrens MM (2012) Behavioral and neurochemical consequences of cortical oxidative stress on parvalbumin-interneuron maturation in rodent models of schizophrenia. Neuropharmacology 62:1322-1331.

Prabakaran S, Swatton JE, Ryan MM, Huffaker SJ, Huang JT, Griffin JL, Wayland M, Freeman T, Dudbridge F, Lilley KS, Karp NA, Hester S, Tkachev D, Mimmack ML, Yolken RH, Webster MJ, Torrey EF, Bahn S (2004) Mitochondrial dysfunction in schizophrenia: evidence for compromised brain metabolism and oxidative stress. Mol Psychiatry 9:684697.

Radonjić NV, Knezević ID, Vilimanovich U, Kravić-Stevović T, Marina LV, Nikolić T, Todorović V, Bumbasirević V, Petronijević ND (2010) Decreased glutathione levels and altered antioxidant defense in an animal model of schizophrenia: long-term effects of perinatal phencyclidine administration. Neuropharmacology 58:739-745.

Ragland JD, Laird AR, Ranganath C, Blumenfeld RS, Gonzales SM, Glahn DC (2009) Prefrontal activation deficits during episodic memory in schizophrenia. Am J Psychiatry 166:863-874.

Rajagopal L, Massey BW, Huang M, Oyamada Y, Meltzer HY (2014) The novel object recognition test in rodents in relation to cognitive impairment in schizophrenia. Curr Pharm Des 20:5104-5114.

Rajasekaran A, Venkatasubramanian G, Berk M, Debnath M (2015) Mitochondrial dysfunction in schizophrenia: pathways, mechanisms and implications. Neurosci Biobehav Rev 48:10-21.

Rego AC, Oliveira CR (2003) Mitochondrial dysfunction and reactive oxygen species in excitotoxicity and apoptosis: implications for the pathogenesis of neurodegenerative diseases. Neurochem Res 28:1563-1574.

Schinder AF, Olson EC, Spitzer NC, Montal M (1996) Mitochondrial dysfunction is a primary event in glutamate neurotoxicity. J Neurosci 16:6125-6133.

Sekar A, Bialas AR, de Rivera H, Davis A, Hammond TR, Kamitaki N, Tooley K, Presumey J, Baum M, Van Doren V, Genovese G, Rose SA, Handsaker RE; Schizophrenia Working Group of the Psychiatric Genomics Consortium, Daly MJ, Carroll MC, Stevens B, McCarroll SA 
(2016) Schizophrenia risk from complex variation of complement component 4. Nature 530:177-183.

Snyder MA, Gao WJ (2013) NMDA hypofunction as a convergence point for progression and symptoms of schizophrenia. Front Cell Neurosci 7:31.

Sohal VS, Rubenstein JLR (2019) Excitation-inhibition balance as a framework for investigating mechanisms in neuropsychiatric disorders. Mol Psychiatry 24:1248-1257.

Sohal VS, Zhang F, Yizhar O, Deisseroth K (2009) Parvalbumin neurons and gamma rhythms enhance cortical circuit performance. Nature 459:698702.

Sorce S, Schiavone S, Tucci P, Colaianna M, Jaquet V, Cuomo V, DuboisDauphin M, Trabace L, Krause KH (2010) The NADPH oxidase NOX2 controls glutamate release: a novel mechanism involved in psychosis-like ketamine responses. J Neurosci 30:11317-11325.

Stefani MR, Moghaddam B (2005) Transient N-methyl-D-aspartate receptor blockade in early development causes lasting cognitive deficits relevant to schizophrenia. Biol Psychiatry 57:433-436.

Steullet P, Cabungcal JH, Monin A, Dwir D, O’Donnell P, Cuenod M, Do KQ (2016) Redox dysregulation, neuroinflammation, and NMDA receptor hypofunction: a "central hub" in schizophrenia pathophysiology? Schizophr Res 176:41-51.

Steullet P, Cabungcal JH, Coyle J, Didriksen M, Gill K, Grace AA, Hensch TK, LaMantia AS, Lindemann L, Maynard TM, Meyer U, Morishita H, O’Donnell P, Puhl M, Cuenod M, Do KQ (2017) Oxidative stress-driven parvalbumin interneuron impairment as a common mechanism in models of schizophrenia. Mol Psychiatry 22:936-943.

Timms AE, Dorschner MO, Wechsler J, Choi KY, Kirkwood R, Girirajan S, Baker C, Eichler EE, Korvatska O, Roche KW, Horwitz MS, Tsuang DW (2013) Support for the N-methyl-D-aspartate receptor hypofunction hypothesis of schizophrenia from exome sequencing in multiplex families. JAMA Psychiatry 70:582-590.

Wang CZ, Yang SF, Xia Y, Johnson KM (2008) Postnatal phencyclidine administration selectively reduces adult cortical parvalbumin-containing interneurons. Neuropsychopharmacology 33:2442-2455.

White RJ, Reynolds IJ (1996) Mitochondrial depolarization in glutamatestimulated neurons: an early signal specific to excitotoxin exposure. J Neurosci 16:5688-5697.

Yan S, Du F, Wu L, Zhang Z, Zhong C, Yu Q, Wang Y, Lue LF, Walker DG, Douglas JT, Yan SS (2016) F1F0 ATP synthase-cyclophilin D interaction contributes to diabetes-induced synaptic dysfunction and cognitive decline. Diabetes 65:3482-3494.

Young JW, Powell SB, Risbrough V, Marston HM, Geyer MA (2009) Using the MATRICS to guide development of a preclinical cognitive test battery for research in schizophrenia. Pharmacol Ther 122:150-202.

Young JW, Amitai N, Geyer MA (2012) Behavioral animal models to assess pro-cognitive treatments for schizophrenia. Handb Exp Pharmacol 213:39-79.

Zaghloul N, Patel H, Codipilly C, Marambaud P, Dewey S, Frattini S, Huerta PT, Nasim M, Miller EJ, Ahmed M (2014) Overexpression of extracellular superoxide dismutase protects against brain injury induced by chronic hypoxia. PLoS One 9:e108168.

Zhang C, Rodriguez C, Spaulding J, Aw TY, Feng J (2012) Age-dependent and tissue-related glutathione redox status in a mouse model of Alzheimer's disease. J Alzheimers Dis 28:655-666.

Zhang Z, Sun QQ (2011) Development of NMDA NR2 subunits and their roles in critical period maturation of neocortical GABAergic interneurons. Dev Neurobiol 71:221-245.

Zhu Y, Carvey PM, Ling Z (2006) Age-related changes in glutathione and glutathione-related enzymes in rat brain. Brain Res 1090:35-44. 